\title{
MONITOREO DEL VIRUS DEL SINDROME DE LA MANCHA BLANCA (WSSV) EN MUESTRAS DE LANGOSTINO (Pleoticus muelleri) DURANTE LOS AÑOS 2010 A 2014 EN LA ARGENTINA
}

\author{
Verónica Jurquiza ${ }^{1}$, Juan de la Garza, Gabriela Andreoli y Paula Moriondo Danovaro \\ Instituto Nacional de Investigación y Desarrollo Pesquero (INIDEP), \\ Paseo Victoria Ocampo No 1, Escollera Norte, B7602HSA - Mar del Plata, Argentina \\ ${ }^{1}$ correo electrónico: jurquiza@inidep.edu.ar
}

RESUMEN. La pesquería de langostino (Pleoticus muelleri), una de las más importantes del Mar Argentino, superó en 2016 el 50\% del valor total de las exportaciones pesqueras. La implementación y desarrollo de controles sanitarios son requisitos del comercio internacional. Entre los patógenos que afectan a los crustáceos se encuentra el virus del síndrome de la mancha blanca (White spot syndrome virus: WSSV) y, según lo establecido por la Organización Mundial de Sanidad Animal (OIE), la enfermedad es de declaración obligatoria. Debido a la necesidad de contar con datos científicos para establecer el estado sanitario del recurso respecto del WSSV, el objetivo del presente trabajo fue relevar en forma continua la infección viral en langostinos salvajes. Se trabajó con muestras capturadas durante 2010-2014 en áreas cercanas a puerto Rawson y el Golfo San Jorge. El total de 506 ejemplares analizados con la técnica de PCR anidada utilizando el Kit Comercial IQ2000 ${ }^{\mathrm{TM}}$ WSSV, método validado por la OIE, resultaron negativos al virus. Se concluye que en los cinco años de monitoreo continuo no se evidenció presencia de WSSV en langostino. Este estudio ofrece una base de datos científicos que ayudaría a garantizar la calidad sanitaria y el comercio internacional de esta pesquería de interés comercial en la Argentina. Además, proporciona herramientas que permitirán proteger el producto ante posibles sanciones y barreras comerciales innecesarias.

Palabras clave: Virus del síndrome de la mancha blanca (WSSV), langostino, Pleoticus muelleri, controles sanitarios, Rawson, Golfo de San Jorge, Argentina.

\section{MONITORING OF THE WHITE SPOT SYNDROME VIRUS (WSSV) IN ARGENTINE RED SHRIMP (Pleoticus muelleri) SAMPLES DURING 2010-2014 IN ARGENTINA}

\footnotetext{
ABSTRACT. Argentine red shrimp (Pleoticus muelleri) fishery, one of the most important in the Argentine Sea, exceeded in $201650 \%$ of the total value of fishing exports. The implementation and development of health controls are requirements of international trade. Among the pathogens that affect crustaceans is the White spot syndrome virus (WSSV) and, according to the World Organisation for Animal Health (OIE), it is a mandatory reportable disease. Due to the need to count on scientific information to establish the sanitary state of the resource with respect to WSSV, the aim of this work was to continuously monitor the viral infection in wild red shrimp. Samples caught in areas close to Rawson port and San Jorge Gulf during 2010-2014 were studied. The total of 506 specimens analized with the nested PCR technique using the IQ2000 ${ }^{\mathrm{TM}}$ WSSV Commercial Kit, a method validated by the OIE, were virus negative. It is concluded that during the five years of continuous monitoring there was no evidence of WSSV in Argentine red shrimp. In this study a scientific data base that would help to guarantee the sanitary quality and international trade for said fishery of commercial interest in Argentina is offered. In addition, tools that would allow to protect the product against possible sanctions and unnecessary trade barriers are provided.
} 
Key words: White spot syndrome virus (WSSV), Argentine red shrimp, Pleoticus muelleri, health controls, Rawson, San Jorge Gulf, Argentina.

\section{INTRODUCCIÓN}

La pesquería del langostino (Pleoticus muelleri) es una de las más importantes del Mar Argentino (Bertuche et al. 1999). La temporada de 2016 fue la cuarta consecutiva con un desembarque declarado que superó las 100.000 t (Fischbach y Bertuche 2017), constituyendo un nuevo récord en la historia. La industria pasó de exportar $44.978 \mathrm{t}$ en 2008 a $160.742 \mathrm{t}$ en 2016. Las exportaciones de langostino en 2016 superaron en valor los 1.000 millones de dólares, más del 50\% del total de las exportaciones pesqueras. El principal destino de las exportaciones es España, luego China, Italia, Japón y Estados Unidos (SSPyA 2016).

La comercialización internacional requiere implementar y desarrollar controles sanitarios. La aparición de agentes patógenos en productos congelados destinados a exportación es causa de gran preocupación debido a que los mismos pueden infectar zonas libres de la enfermedad y, a la vez, limitar el acceso a los mercados internacionales (Roccamo et al. 2010; Costagliola et al. 2011).

El Código Sanitario para los Animales Acuáticos (Código Acuático) de la Organización Mundial de Sanidad Animal (OIE) establece las normas para mejorar la sanidad de los animales acuáticos y promover el comercio internacional seguro. Las autoridades competentes de los países importadores y exportadores deben remitirse a las normas sanitarias del Código Acuático durante las actividades de detección temprana, notificación y control de agentes patógenos. El Acuerdo sobre la Aplicación de Medidas Sanitarias y Fitosanitarias (Acuerdo MSF) de la Organización Mundial del Comercio (OMC) reconoce formalmente el papel de la OIE como la organización normativa en el campo de la sanidad animal y las enfermedades zoonóticas.
La OIE publica dos códigos (Terrestre y Acuático) y dos Manuales (Terrestre y Acuático) que constituyen las principales referencias para los miembros de la OMC. En el citado código se incluyen los agentes patógenos y las enfermedades que se consideran objetivo según los siguientes criterios: que sea causa de pérdidas importantes de producción a nivel nacional o multinacional; que afecte negativamente a poblaciones de animales acuáticos salvajes, o bien que el agente causal tenga importancia para la salud pública. En 2005, se constituyó un grupo ad hoc que propuso una nueva lista de enfermedades que reunían los criterios mencionados y que entró en vigencia en 2006 (OIE 2016a).

El virus del síndrome de la mancha blanca (White spot syndrome virus: WSSV) es uno de los principales patógenos que afectan al camarón y otros crustáceos (Maeda et al., 2000). La OIE ha indicado que la enfermedad causada por el WSSV, caracterizada por ser una infección de curso agudo y de rápida mortalidad, en caso de ocurrir, debe ser declarada obligatoriamente (Bustillo-Ruiz et al. 2009; OIE 2016a).

El WSSV recibe su nombre debido a que la infección puede inducir la disfunción del tegumento que resulta en la acumulación de sales de calcio dentro de la cutícula, dando lugar a manchas blancas. Otros signos de la enfermedad pueden ser: cambio de coloración a rojo en el cuerpo y apéndices, provocada por la expansión de los cromatóforos; letargo y reducción en el consumo de alimentos (Escobedo-Bonilla et al. 2008; Sánchez-Paz 2010).

Hasta la fecha, varios estudios han demostrado que existen múltiples vías de transmisión y potenciales reservorios (Chou et al. 1995; Sánchez-Paz 2010). La tasa de mortalidad puede llegar a ser del $100 \%$ en estanques de cultivo (Sahul et al. 2001). En la actualidad, no existen tratamientos terapéuticos disponibles para prevenir o reducir 
los efectos de este virus y la vigilancia de esta enfermedad, como así también las diferentes metodologías implementadas para su detección, brindan apoyo y fortalecimiento a la industria y han sido fuertemente recomendadas (Bateman et al. 2012; Tsai et al. 2012).

El primer brote de WSSV fue reportado en Japón en granjas de cultivo durante 1992 y 1993 y aproximadamente al mismo tiempo fue descubierto en Taiwán, diseminándose rápidamente en toda la región asiática. En América, el primer caso se reportó en Texas en 1995 en una granja de cultivo de Penaeus setiferus; en 1999 se detectó en Panamá y posteriormente se dispersó a México, Nicaragua, Honduras, Costa Rica, Ecuador y Colombia (Lightner y Redman 1998; Lightner y Pantoja 2003; Hasson et al. 2006).

Varios métodos moleculares han sido desarrollados para la detección de este patógeno. El Manual Acuático de la OIE establece como métodos de elección la PCR (reacción en cadena de la polimerasa) anidada y la qPCR (reacción en cadena de la polimerasa en tiempo real) mediante el uso de sondas de hidrólisis (OIE 2016b).

Actualmente, a través de la empresa GeneReach Biotechnology Corp., existe en el mercado el Kit de Diagnóstico IQ2000 ${ }^{\mathrm{TM}}$ WSSV (2008), que consiste en un sistema de detección del WSSV mediante la técnica de PCR anidada. Este kit, de acuerdo con la Resolución No 26/2013 de la OIE, se encuentra validado y apto para el diagnóstico de la Enfermedad de las Manchas Blancas (WSD, White spot disease, por sus siglas en inglés) en crustáceos, con las siguientes finalidades: certificar la ausencia de infección $(<10$ viriones/reacción) en animales o productos destinados al comercio o el desplazamiento; confirmar el diagnóstico de casos sospechosos o clínicos y calcular la prevalencia de la infección para facilitar el análisis de riesgos.

En la Argentina, fue realizado un primer estudio de optimización de técnicas de detección de agentes virales en $P$. muelleri (Bate, 1988) en el estuario de Bahía Blanca, en el cual no fue detec- tado el virus en las muestras analizadas (Roccamo et al. 2010). Por otro lado, ese mismo año Martorelli et al. (2010) mencionan lo que sería, sin confirmar, la primera detección de WSSV en crustáceos del Estuario de Bahía Blanca. Dicha situación afectó el comercio internacional de una de las principales especies de crustáceos explotadas comercialmente, el langostino del Mar Argentino y alertó a las autoridades nacionales del sector sanitario y pesquero sobre la necesidad de realizar monitoreos sistemáticos para contar con información científica acerca de la presencia o ausencia del WSSV en crustáceos del Mar Argentino.

Tanto el Instituto Nacional de Investigación y Desarrollo Pesquero (INIDEP) como el Servicio Nacional de Sanidad y Calidad Agroalimentaria (SENASA), junto con la Subsecretaría de Pesca y Acuicultura de la Nación, llevaron adelante estudios epidemiológicos para evaluar el estado sanitario de las poblaciones silvestres de langostinos de la especie $P$. muelleri. Se presentaron informes y trabajos a congresos, no detectándose el WSSV en ninguno de los estudios realizados (SENASA 2011, 2013; Costagliola et al. 2011, 2013). Sin embargo, esta situación puso en evidencia la necesidad de realizar una vigilancia en un período de tiempo determinado, tal cual lo establece la OIE, para poder determinar el estado sanitario del langostino.

Teniendo en cuenta el contexto actual, el objetivo del presente trabajo fue realizar un monitoreo del WSSV en forma continua, durante un período de tiempo determinado, en langostinos silvestres provenientes del Golfo San Jorge y áreas aledañas a Rawson, con el fin de aportar datos científicos para asegurar la calidad sanitaria y el comercio internacional. Adicionalmente, se proveen herramientas para salvaguardar el producto ante posibles sanciones de los distintos mercados internacionales con respecto a este tema de sanidad animal, evitando la creación de barreras comerciales innecesarias. 


\section{MATERIALES Y MÉTODOS}

La investigación se realizó en conjunto entre el Gabinete de Biología Molecular y Microbiología y el Programa "Pesquerías de Crustáceos", dentro de la Dirección de Pesquerías de Invertebrados, Peces Pelágicos y Ambiente Marino del INIDEP. Se desarrolló teniendo en cuenta las recomendaciones internacionales del Código Sanitario y del Manual de Diagnóstico para los Animales Acuáticos de la OIE.

Durante los años 2010 a 2014 se realizaron seis muestreos de langostino capturados en áreas cercanas al puerto de Rawson y en el Golfo San Jorge, en el área comprendida entre $43^{\circ} \mathrm{S}$ y $47^{\circ} \mathrm{S}$, al oeste de $63^{\circ} \mathrm{W}$. En la Tabla 1 se detallan las características de cada muestreo y el número de ejemplares analizados. Se registró el número y ubicación de los lances de pesca, así como el sexo y la talla de los langostinos analizados. En todos los casos, se realizó una evaluación macroscópica de cada ejemplar, con el objeto de identificar signos clínicos de enfermedad. Posteriormente, luego de la captura, las muestras fueron conservadas en etanol $96 \%$ en recipientes individuales, hasta su procesamiento en el Gabinete de Biología Molecular y Microbiología del INIDEP. En la Figura 1 se observa la localización de los lances de pesca de la flota costera comercial durante las fechas en que fueron obtenidas las muestras y en la Figura 2 se detallan los sitios de muestreo en las campañas de investigación, realizadas por los buques de investigación pesquera (BIPs) del INIDEP.

En la zona de Rawson se muestrearon ejemplares adultos machos y hembras en diferentes estadíos de maduración (inmaduro, maduro y en reproducción), con una talla desde 32 a $53 \mathrm{~mm}$ por ejemplar. En el Golfo San Jorge se muestrearon, además, ejemplares juveniles.

\section{Metodología}

Se utilizó el Kit de diagnóstico IQ2000 ${ }^{\mathrm{TM}}$ para la detección del WSSV, mediante la técnica de PCR anidada. Este sistema de detección y prevención puede diferenciar los crustáceos infectados en cuatro niveles diferentes de infección: muy ligero, ligero, medio y severo, de acuerdo con las referencias del kit (Figura 3). El kit provee un control positivo con $10^{4}$ copias $\mu 1^{-1}$ (plásmido conteniendo una secuencia parcial del virus), un control negativo (Yeast tRNA (40 ng $\left.\mu \mathrm{l}^{-1}\right)$ ) y un

Tabla 1. Detalle de los muestreos realizados a bordo de buques de investigación pesquera (BIP) y embarcaciones comerciales. Se incluye fecha de muestreo, zona y número de ejemplares muestreados.

Table 1. Detail of the samplings performed on board of research fishing vessels (RFV) and commercial vessels. The sampling date, zone and number of specimens sampled are included.

\begin{tabular}{|c|c|c|c|c|}
\hline Año & $\begin{array}{l}\text { Fecha de } \\
\text { muestreo }\end{array}$ & $\begin{array}{c}\mathrm{N}^{\mathrm{o}} \text { de ejemplares } \\
\text { muestreados }\end{array}$ & Zona de muestreo & BIP/Embarcación comercial \\
\hline 2010 & Noviembre 2010 & 50 & Rawson & "San Guiseppe II" \\
\hline \multirow[t]{3}{*}{2011} & Enero 2011 & 30 & Rawson & "Virgen del Milagro" \\
\hline & & & Rawson & "Nueva Neptunia I" \\
\hline & Marzo 2011 & 95 & Rawson & “Don José Di Bonna" \\
\hline 2012 & Noviembre 2012 & 70 & Rawson & "Don José Di Bonna" \\
\hline 2013 & Marzo 2013 & 180 & Rawson & BIP “Capitán Oca Balda” OB-01/2013 \\
\hline 2014 & Febrero 2014 & 154 & Golfo de San Jorge & BIP “Capitán Oca Balda” OB-01/2014 \\
\hline
\end{tabular}



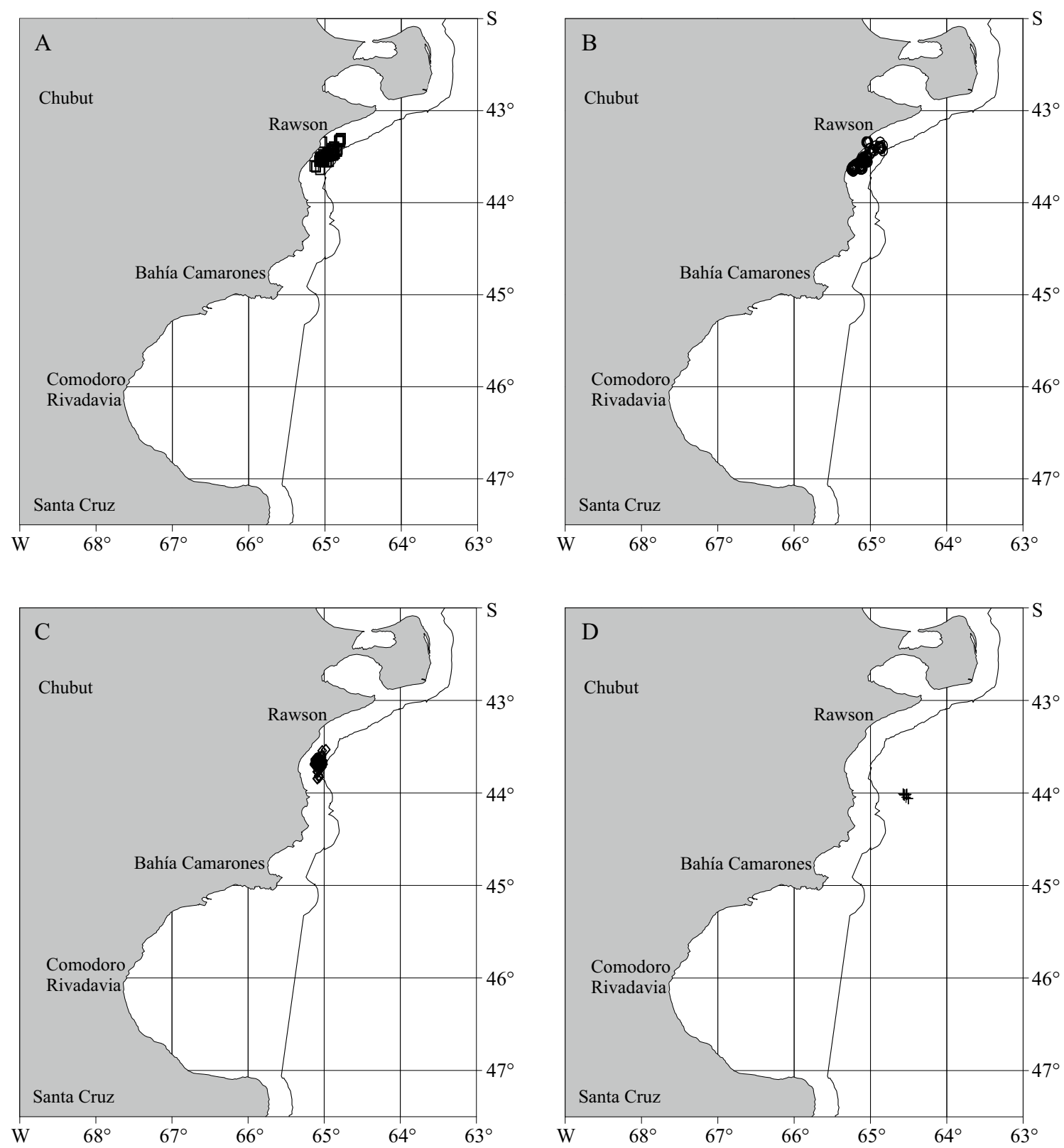

Figura 1. Detalle de los sitios de muestreo de las campañas realizadas a bordo de buques comerciales: "San Guiseppe II" (A), "Virgen del Milagro" (B), "Nueva Neptunia I" (C) y "Don José Di Bonna" (D).

Figure 1. Detail of the sampling sites of the cruises carried out on board of commercial vessels: "San Guiseppe II" (A), "Virgen del Milagro" (B), "Nueva Neptunia I" (C) y "Don José Di Bonna" (D).

marcador de peso molecular con bandas de 848 , 630 y $333 \mathrm{pb}$ (pares de bases).

A continuación, se detallan los protocolos de extracción de ácido desoxirribonucleico (ADN), amplificación del WSSV por PCR anidada y visualización de los productos de PCR. 

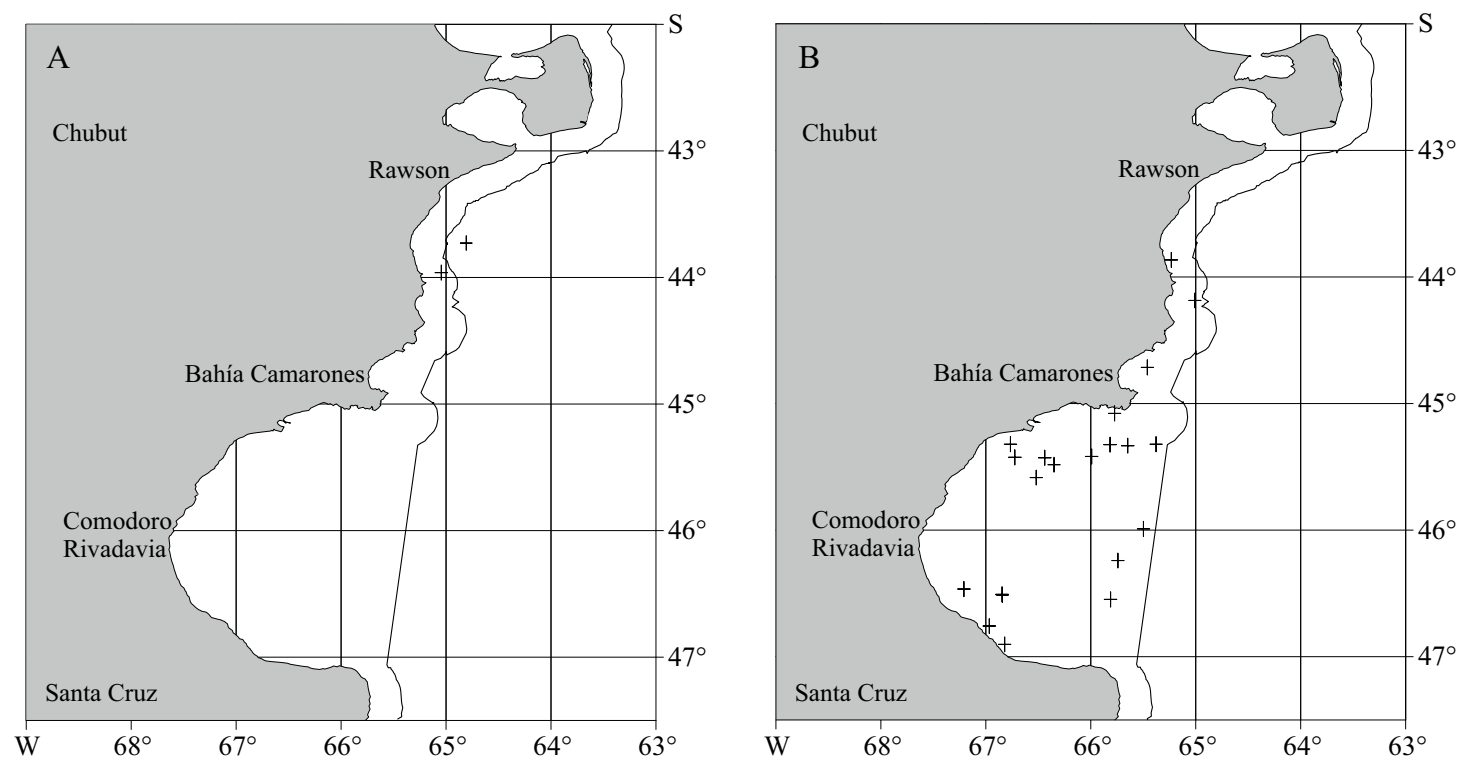

Figura 2. Detalle de los sitios de muestreo de las campañas de investigación realizadas a bordo de buques de investigación pesquera del INIDEP. A) “Capitán Oca Balda” OB-01/2013. B) “Capitán Oca Balda” OB-01/2014.

Figure 2. Detail of the sampling sites of the research cruises carried out on board of INIDEP RFV. A) "Capitán Oca Balda" OB-01/2013. B) "Capitán Oca Balda” OB-01/2014.
1
2
3
4
5
6
7
8
9
M

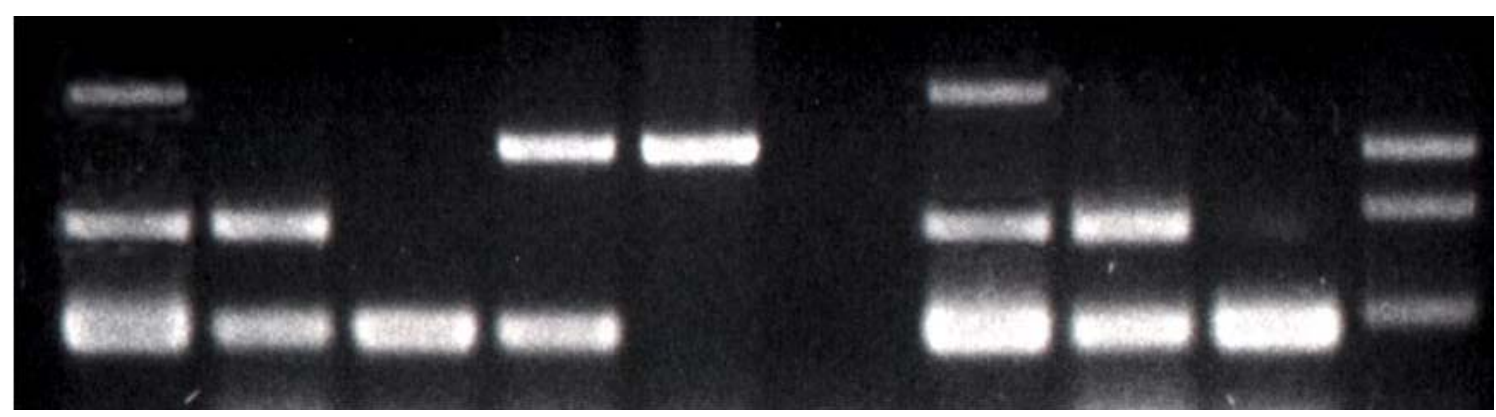

Figura 3. Foto obtenida del kit mostrando el gel de electroforesis de referencia para evaluar el tipo de resultado obtenido. Las muestras positivas y estándar se observan en los siguientes modelos de gel: 1) muestra de infección severa de WSSV, 2) muestra de infección media de WSSV, 3) muestra de infección baja de WSSV, 4) muestra de infección muy baja de WSSV, 5) muestra negativa de WSSV, 6) ddH2O, 7) estándar 1 de 2.000 copias/reacción, 8) estándar 2 de 200 copias/reacción, 9) estándar 3 de 20 copias/reacción, M) marcador de peso molecular de 848, 630, 333 pb. Las muestras negativas muestran solo una banda de $848 \mathrm{pb}$, producto del control interno de amplificación. pb: pares de bases (IQ2000 ${ }^{\mathrm{TM}}$ WSSV, 2008).

Figure 3. Picture obtained from the kit indicating reference electrophoresis gel to evaluate the type of result obtained. The positive and standard samples are observed in the following gel models: 1) WSSV severe infection sample, 2) WSSV mean infection sample, 3) WSSV low infection sample, 4) WSSV very low infection sample, 5) WSSV negative sample, 6) ddH2O, 7) standard 1 of 2.000 copies/reaction, 8) standard 2 of 200 copies/reaction, 9) standard 3 of 20 copies/reaction, M) molecular weight marker of 848,630, $333 \mathrm{bp}$. The negative samples show only one band of 848 bp, product of the internal amplification control. bp: base pairs (IQ2000 ${ }^{T M}$ WSSV, 2008). 


\section{Extracción de ADN}

La extracción de ADN se realizó a partir de músculo de pleópodo de langostino, de acuerdo con las especificaciones del Kit Comercial IQ2000 ${ }^{\mathrm{TM}} \mathrm{WSSV}$, con solución de lisis, según instrucciones del fabricante. Se homogeneizaron $25 \mathrm{mg}$ de músculo de pleópodo con $500 \mu \mathrm{l}$ de solución de lisis y luego se incubó a $95{ }^{\circ} \mathrm{C}$ durante $10 \mathrm{~min}$. Se centrifugó a $12.000 \mathrm{rpm}$ durante $10 \mathrm{~min}$ a temperatura ambiente. Se transfirieron $200 \mu 1$ del sobrenadante a un tubo con $400 \mu 1$ de etanol 95\%. Se homogeneizó en vórtex durante $30 \mathrm{~s}$ y se centrifugó a $12.000 \mathrm{rpm}$ durante $5 \mathrm{~min}$ a temperatura ambiente. Se decantó el etanol y se secó el precipitado de ADN durante $15 \mathrm{~min}$ a $2 \mathrm{~h}$ a $37^{\circ} \mathrm{C}$. Finalmente, el precipitado de ADN se disolvió en un volumen de $200 \mu 1$ de agua calidad molecular y se conservó a $-20{ }^{\circ} \mathrm{C}$.

La calidad e integridad del ADN extraído se evaluó mediante un control interno de amplificación provisto por el kit. Se utilizaron cebadores específicos de decápodos que corresponden a una secuencia conservada del ARNr 18S (143F 5, TGCCTTATCAGCTNTCGATTGTAG 3' y 145R 5' TTCAGNTTTGCAACCATACTTCCC 3') que generan un amplicón de 848 pb.

\section{Amplificación del virus del síndrome de la mancha blanca (WSSV) por PCR}

Se determinaron las condiciones óptimas de la reacción con el control positivo y luego se analizaron las muestras. Se aplicó la técnica de PCR anidada, dividida en dos etapas y se utilizó un termociclador marca Biometra.

Para la primera etapa de amplificación se utilizó un volumen final de $10 \mu \mathrm{l}$. A cada tubo se le agregaron $2 \mu \mathrm{l}$ de $\mathrm{ADN}, 7,5 \mu \mathrm{l}$ de la pre-Mix y $0,5 \mu \mathrm{lde}$ la IQzyme ADN polimerasa. Además de las muestras a analizar, se utilizó un control negativo y un control positivo provistos por el kit. Las condiciones de amplificación fueron: 5 ciclos de $30 \mathrm{~s}$ a 94 ${ }^{\circ} \mathrm{C}, 30 \mathrm{~s}$ a $62{ }^{\circ} \mathrm{C}$ y $30 \mathrm{~s}$ a $72{ }^{\circ} \mathrm{C} ; 15$ ciclos de $15 \mathrm{~s} \mathrm{a}$ $94{ }^{\circ} \mathrm{C}, 15 \mathrm{~s}$ a $62{ }^{\circ} \mathrm{C}, 20 \mathrm{~s}$ a $72{ }^{\circ} \mathrm{C}$, y una extensión final que consistió en $30 \mathrm{~s}$ a $72{ }^{\circ} \mathrm{C}$ y $30 \mathrm{~s}$ a $20^{\circ} \mathrm{C}$.
Para la segunda etapa de amplificación (anidada), se utilizó un volumen final de $25 \mu 1$. A cada tubo de la reacción de PCR anterior terminada $(10 \mu \mathrm{l})$ se le agregaron $14 \mu \mathrm{l}$ de la Mix PCR anidado y $1 \mu \mathrm{l}$ de la IQzyme ADN polimerasa. Las condiciones de amplificación fueron: 25 ciclos de $20 \mathrm{~s}$ a $94{ }^{\circ} \mathrm{C}, 20 \mathrm{~s}$ a $62{ }^{\circ} \mathrm{C}$ y $30 \mathrm{~s}$ a $72{ }^{\circ} \mathrm{C}$; y una extensión final que consistió en $30 \mathrm{~s}$ a $72{ }^{\circ} \mathrm{C}$.

Obtener un resultado positivo en la primer etapa de este protocolo estándar significaría una infección grave por el WSSV, la sensibilidad es de aproximadamente 20.000 copias de un plásmido molde. Mientras que, un resultado positivo solo en la segunda etapa de amplificación, indicaría una infección latente o con estado de portador. La sensibilidad global de ambos pasos es de unas 20 copias de un plásmido molde del WSSV (OIE 2016).

\section{Visualización de los productos de PCR}

Los productos resultantes de la amplificación del ADN fueron cargados en geles de agarosa al $2 \%$ con bromuro de etidio $\left(0,5 \mu \mathrm{g} \mathrm{ml}^{-1}\right)$, sometidos a electroforesis y luego observados en un transiluminador de luz ultravioleta. Para la corrida electroforética, se utilizó un marcador de peso molecular con bandas de 848, 630 y 333 pb provisto por el kit y el gel se corrió en Buffer TAE $1 \mathrm{X}$ durante 20-30 min a $90 \mathrm{~V}$.

\section{RESULTADOS}

Se analizaron un total de 506 ejemplares de langostino en los cuales, macroscópicamente, no se detectaron signos clínicos de enfermedad compatibles con WSD. Externamente no mostraron lesiones a nivel cuticular ni signos visibles de melanosis. Tampoco se registraron mortandades anormales en las poblaciones silvestres estudiadas.

Los resultados de los ensayos de PCR anidada se presentan en la Tabla 2, en la cual se identifica el número de ejemplares muestreados/analizados 
y la campaña correspondiente. No se ha detectado la secuencia específica del WSSV en ninguna de las muestras analizadas, todas resultaron negativas. En la Figura 4 se observa un gel de agarosa con los productos resultantes de la amplificación del ADN por la técnica de PCR anidada, las calles $1-5$ corresponden a las muestras estudiadas, se observa una banda de $848 \mathrm{pb}$ correspondiente al control interno de amplificación, mientras que no se observan las bandas de $296 \mathrm{pb}$ y/o $550 \mathrm{pb}$ que darían positiva la reacción. La calle 6 es el control negativo, que con-

Tabla 2. Resultados del análisis de PCR anidada para detectar el WSSV en muestras de Pleoticus muelleri.

Table 2. Results of the nested PCR analysis to detect WSSV in Pleoticus muelleri samples.

\begin{tabular}{lccc}
\hline Año & $\begin{array}{c}\text { No de ejemplares } \\
\text { muestreados }\end{array}$ & $\begin{array}{c}\mathrm{N}^{\text {o }} \text { de ejemplares } \\
\text { analizados }\end{array}$ & Resultado PCR WSSV \\
\hline 2010 & 50 & 50 & Negativo \\
2011 & 125 & 125 & Negativo \\
2012 & 70 & 70 & Negativo \\
2013 & 180 & 107 & Negativo \\
2014 & 154 & 154 & Negativo \\
\hline
\end{tabular}

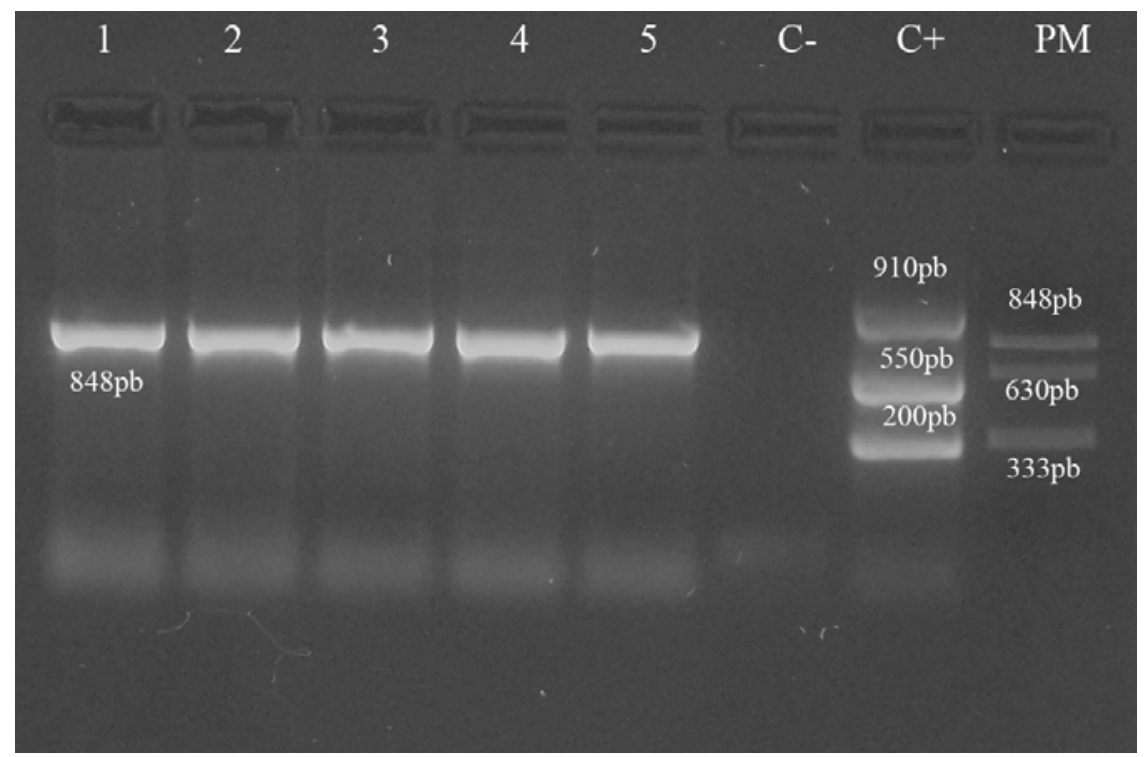

Figura 4. PCR anidada para detectar el WSSV. Electroforesis en gel de agarosa, 1-5: muestras negativas de WSSV (control interno de amplificación $848 \mathrm{pb}$ ), C-: control negativo, $\mathrm{C}+$ : control positivo: $10^{4}$ copias $\mu \mathrm{l}^{-1}$ de plásmido que contiene una secuencia parcial del WSSV, PM: marcador de peso molecular con bandas de 848, 630 y 333 pb, respectivamente.

Figure 4. Nested PCR to detect WSSV. Agarose gel electrophoresis, 1-5: WSSV negative samples (internal control of 848 bp amplification), $C-:$ negative control, $C+$ : positive control: $10^{4}$ copies $\mu l^{-1}$ of plasmid containing a partial sequence of the WSSV, PM: molecular weight marker with bands of 848, 630 and $333 \mathrm{bp}$, respectively. 
tiene el plásmido yeast $t$ RNA sin la secuencia específica del virus. La calle 7 es el control positivo, compuesto por $10^{4}$ copias $\mu 1^{-1}$ de plásmido conteniendo una secuencia parcial del virus del WSSV. Se observan las bandas de 296, 550 y $910 \mathrm{pb}$, que demuestran la efectividad de la reacción. La calle 8 corresponde al marcador de peso molecular, donde se detectan las bandas de 848, 630 y 333 pb, respectivamente.

\section{DISCUSIÓN}

Este es el primer estudio de monitoreo continuo durante cinco años del WSSV en muestras de langostino en la zona de Rawson y Golfo San Jorge, en el cual no se detectó el virus en ninguna de las muestras analizadas. El resultado coincide con lo publicado por Roccamo et al. (2010) en el Estuario de Bahía Blanca y por el Ministerio de Agroindustria de la Nación y el SENASA, quienes informaron en forma conjunta la ausencia de esta patología en langostinos provenientes del Golfo San Jorge, utilizando la misma metodología de muestreo y analizando por histopatología y PCR (SENASA 2011, 2013; Raibenberg et al. 2012, 2014).

En la Argentina, los antecedentes respecto al diagnóstico de WSSV solo incluyen dos estudios sobre lo que sería la primera detección en crustáceos (Palaemon macrodactylus, Artemesia longinaris y Cyrtograpsus angulatus) del Estuario de Bahía Blanca (Martorelli et al. 2010; 2012); no hay reportes en crustáceos naturales de interés comercial, ni tampoco de enfermedad clínica. Según el Manual de la OIE, la PCR anidada de dos pasos y la secuenciación son algunas de las técnicas utilizadas y recomendadas para la vigilancia, detección y diagnóstico del WSSV, y aclara que para diagnosticar la infección en nuevos hospedadores sospechosos debe secuenciarse el fragmento de ADN amplificado a partir de la PCR de dos pasos (Claydon et al. 2004). Cabe considerar que en la metodología utilizada por
Martorelli et al. (2010) no está expuesto que se haya realizado ninguna verificación (secuenciación) de los productos obtenidos por PCR; la OIE afirma que cuando un resultado positivo por PCR de dos pasos no se puede confirmar como WSSV por secuenciación, se considerará negativo. Por lo expuesto y en concordancia con lo publicado por Costagliola et al. (2013), la determinación informada por Martorelli et al. $(2010,2012)$ debería considerarse como un hallazgo no confirmado. Por otra parte, una publicación reciente del mismo autor menciona la ausencia del virus en un monitoreo durante los años 2010 a 2014 en crustáceos del estuario de Bahía Blanca (Martorelli et al. 2017). Por lo tanto, no podría concluirse que el WSSV esté presente en el Mar Argentino. Además, nuestros resultados de ausencia del WSSV en langostino durante cinco años de monitoreo continuo estarían reforzando dichas conclusiones.

Por otra parte, es importante destacar que las muestras de crustáceos en los cuales se habría detectado WSSV fueron extraídas de ambientes estuariales, muy diferentes de las áreas oceánicas donde se captura el langostino patagónico (Costagliola et al. 2013). El área donde se realizó este trabajo, zonas aledañas a Rawson y el Golfo San Jorge, resulta representativa para llevar adelante estudios de monitoreo del WSSV, debido a que concentra el $96 \%$ de las actividades de pesca, desembarco y producción del langostino para su comercialización, tanto para mercado interno como para exportación (Fischbach et al. 2006).

En nuestros resultados se observó que el kit de diagnóstico IQ2000 ${ }^{\mathrm{TM}}$ WSSV, junto con la técnica de PCR anidada de dos pasos (Lo et al. 1996), funcionó bien para analizar muestras de langostino. A pesar de que la totalidad de las muestras resultaron negativas, con el control interno de amplificación provisto por el kit se logró descartar inhibición de la PCR y se comprobó la buena calidad del ADN desechándose, de esta manera, resultados falsos negativos. Los controles internos de amplificación aumentan la fiabilidad de la PCR de diagnóstico (Jurquiza y Quintana 2016). 


\section{CONCLUSIONES}

No se evidenció la presencia del virus del síndrome de la mancha blanca (WSSV) en langostino desembarcado en la zona de Rawson y el Golfo San Jorge, durante los cinco años de monitoreo continuo comprendidos entre 2010 a 2014, resultando negativas la totalidad de las muestras estudiadas por la técnica de PCR anidada.

Este trabajo realizado bajo las recomendaciones y los procedimientos diagnósticos de la OIE, aporta información que permite inferir sobre la ausencia del WSSV en Pleoticus muelleri, en la Argentina. Además, proporciona datos científicos que podrían utilizarse de sustento para que el país pueda declararse en condición de libre de la enfermedad de la mancha blanca; así como también, ofrece una herramienta técnica y rápida a las autoridades nacionales para asegurar la calidad sanitaria del producto en cuanto al comercio internacional.

\section{AGRADECIMIENTOS}

Expresamos agradecimiento al Gabinete de Muestreo, a cargo del Téc. Pablo Izzo por su colaboración en el muestreo de 2010 y 2011, a la Biot. Andrea Salomone por su participación en la preparación de las muestras de 2014, al Lic. Daniel Bertuche, Lic. Carina Fischbach y Farm. Marcela Costagliola por sus aportes. Contribución INIDEP N ${ }^{\circ} 2160$.

\section{BIBLIOGRAFÍA}

Bateman KS, Tew I, French C, Hicks RJ, Martin P, Munro J, Stentiford GD. 2012. Susceptibility to infection and pathogenicity of
White Spot Disease (WSD) in non-model crustacean host taxa from temperate regions. J Inverteb Pathol. 110: 340-351.

Bertuche D, Fischbach C, Roux A, Fernández M, PIÑERo R. 1999. Caracterización de la pesquería de langostino y diagnóstico del estado del recurso en 1999. Inf Téc Int DNI-INIDEP $\mathrm{N}^{\circ} 69 / 1999.15 \mathrm{p}$.

Bustillo-Ruiz MI, Escobedo-Bonilla CM, Sotelo-Mundo RR. 2009. A review of pathogenesis and molecular strategies against white spot syndrome virus of penaeid shrimp. Rev Biol Mar Oceanog. 44: 1-11.

Chou Hy, Huang CY, Wang CH, Chiang HC, Lo CF. 1995. Pathogenicity of a baculovirus infection causing white spot syndrome in cultured penaeid shrimp in Taiwan. Dis Aquat Organ. 23: 165-173.

Claydon K, Cullen B, Owens L. 2004. OIE white spot syndrome virus PCR gives falsepositive results in Cherax quadricarinatus. Dis Aquat Org. 62: 265-268.

Costagliola M, Fischbach C, Jurquiza V, DE la Garza J, Molinari G, Bertuche D. 2013. Situación sanitaria actual de la pesquería del langostino patagónico (Pleoticus muelleri) en relación al Virus del Síndrome de la Mancha Blanca (WSSV) en Argentina. Inf Téc Of INIDEP N ${ }^{\circ} 1 / 2013.10 \mathrm{p}$.

Costagliola M, Fischbach K, Jurquiza V, Spanjersberg G, Moriondo P, Andreoli G, DE LA Garza J. 2011. Ausencia del Virus del Síndrome de la Mancha Blanca (WSSV) en muestras de langostino (Pleoticus muelleri) desembarcado en el Puerto de Rawson entre noviembre de 2010 y marzo de 2011. Inf Invest INIDEP N ${ }^{\circ}$ 66/2011. $11 \mathrm{p}$.

Escobedo-Bonilla CM, Alday-Sanz V, Wille M, Sorgeloos P, Pensaert MB, Nauwynck HJ. 2008. A review on the morphology, molecular characterization, morphogenesis and pathogenesis of white spot syndrome virus. J Fish Dis. 31: 1-18.

Fischbach C, Bertuche D. 2017. Pesquería del 
langostino, temporada 2016. Inf Téc Of INIDEP $\mathrm{N}^{\mathrm{o}} 7 / 2017.23 \mathrm{p}$.

Fischbach C, DE DA Garza J, Bertuche D. 2006. La pesquería del langostino patagónico en el período 1991-2005. Inf. Téc. INIDEP $\mathrm{N}^{\circ}$ 3/2006. 21 p.

Hasson KW, Fan Y, Reisinger T, Venuti J, VARNER PW. 2006. White-spot syndrome virus (WSSV) introduction into the Gulf of Mexico and Texas freshwater systems through imported, frozen bait-shrimp. Dis Aquat Organ. 71: 91-100.

IQ2000 TM WSSV. 2008. Instruction Manual. Manufacturer: GeneReach Biotecnology Corp. Fitness for purpose valitated and certified by OIE. Register number: 20080304.

Jurquiza V, Quintana S. 2016. Desarrollo de una técnica de reacción de la polimerasa en tiempo real (RT-PCR), con Evagreen como agente intercalante, para la detección del Virus del Síndrome de la Mancha Blanca (WSSV) en crustáceos. Inf Invest INIDEP No 87/2016. 14 p.

Lightner D, Pantoja C. 2003. Manual para el diagnóstico de Enfermedades del Camarón. United Stated Department of Agriculture (USDA). 92 p.

Lightner D, Redman RM. 1998. Shrimp diseases and current diagnostic methods. Aquaculture. 164: 201-220.

Lo CF, Leu JH, Ho CH, Chen CH, Peng SE, Chen YT, Chou CM, Yeh PY, Huang CJ, Chou HY, eT AL. 1996. Detection of baculovirus associated with white spot syndrome (WSBV) in penaeid shrimp using polymerase chain reaction. Dis Aquat Org. 25: 133-141.

Maeda M, Itami T, Mizuki E, TanaKa R, YoshiZU Y, DOI K, YASUNAGA-AOKI C, TAKAHASHI Y, KAWARABATA T. 2000. Red swamp crawfish (Procambarus clarkii): an alternative experimental host in the study of white spot syndrome virus. Acta Virol. 44: 371-374.

Martorelli S, Overstreet R, JaVONOVich J. 2010. First report of viral pathogens WSSV and IHHNV in Argentine crustaceans. Bull Mar Sci. 86 (1): 117-131.

Martorelli SR, Marcotegui P, Montes M, PANEI CJ. 2017. Screening for WSSV in crustacean from marine areas of Buenos Aires, Argentina. Examen para WSSV en crustáceos de áreas marinas de Buenos Aires, Argentina. Rev Biol Mar Oceanogr. 52: 635-639.

Martorelli S, Alda MP, Marcotegui PS, MonTES MM, LA SALA L. 2012. New locations and parasitological findings for the invasive shrimp Palaemon macrodactylus in emperate southwestern Atlantic coastal waters. Aq Biol. 15: 153-157.

[OIE] Organización Mundial de Sanidad AnIMAL. 2016a. Código Sanitario para los animales acuáticos. [consultado 30 septiembre 2016]. http://www.oie.int/es/normas-interna cionales/codigo-acuatico/acceso-en-linea.

[OIE] Organización Mundial de Sanidad AnIMAL. 2016b. Manual de Pruebas de Diagnóstico para los animales acuáticos. Parte 2. Sección 2.2 Capítulo 2.2.7. [consultado 30 septiembre 2016]. http://www.oie.int/es/normasinternacionales/manual-acuatico/acceso-enlinea.

Raibenberg F, Ballete CI, Alvarez MA, Cannilla ML, Zenobi C, Alcober-JazbeC M, Ferreyra Armas MC, Escobar E, SAnguiNETti R, Romano LA. 2012. Primary diagnosis and surveillance of notifiable viral diseases of crustaceans in wild red shrimp Pleoticus muelleri in the gulf San Jorge, Argentina. Proceedings of AQUA2012, Praga.

Raibenberg F, Ballete CI, Alvarez M.A., CANnilla ML, Zenobi C, Alcober-Jazbec M, Ferreyra Armas MC, Escobar E, SanGUINETTI R, ROMANO LA. 2014. Molecular and histopathologic survey of OIE notifiable viral diseases in the native wild red prawn Pleoticus muelleri from Rawson, Argentina. Proceedings of WAS2014, Adelaide.

Roccamo AM, Cervellini PM, Piccolo MC, BARRANTES FJ. 2010. Optimización de una 
técnica para la detección de patologías virales en Pleoticus muelleri (Bate, 1988) en el estuario de Bahía Blanca, Argentina. GEOACTA. 35: 40-47.

SÁnchez-PAZ A. 2010. White spot syndrome virus: an overview on an emergent concern. Vet Res. 41 (6): 41-43.

Sahul Hameed AS, Yoganandhan K, Sathish S, Rasheed M, Murugan V, Jayaraman K. 2001. White spot syndrome virus (WSSV) in two species of freshwater crabs (Paratelphusa hydrodomous and P. pulvinata). Aquaculture. 201: 179-186.

[SENASA] Servicio Nacional de Sanidad y CAlidad Agroalimentaria. 2011. Estudio epidemiológico para la determinación del estado sanitario de las poblaciones silvestres de langostinos de la especie Pleoticus muelleri en la República Argentina. Programa de Enfermedades de los Animales Acuáticos. Dirección de Programación Sanitaria Dirección Nacional de Sanidad Animal SENASA. [consultado 26 junio 2017]. https://viejaweb. senasa.gov.ar/Archivos/FileFile7245Informe estudio_epidemiologico_enfermedades crustaceos2.pdf.

[SENASA] Servicio Nacional DE SANidad Y CAlidad Agroalimentaria. 2013. Estudio epidemiológico de las enfermedades Mancha Blanca, Mionecrosis Infecciosa, Necrosis
Hematopoyética e Hipodérmica Infecciosa, Sindrome de Taura y Cabeza Amarilla, en poblaciones silvestres de langostino para la determinación del estado sanitario de las poblaciones silvestres de langostinos (Pleoticus muelleri) en el Golfo San Jorge, República Argentina. Programa de Enfermedades de los Animales Acuáticos. Dirección de Programación Sanitaria, Dirección Nacional de Sanidad Animal SENASA. 20 p.

[SSPYA] Subsecretaria de Pesca y AcuicultuRA. 2016. Dirección de Economía Pesquera. Exportaciones e importaciones pesqueras 2016. [consultado 26 junio 2017]. http://www. agroindustria.gob.ar/sitio/areas/pesca maritima/informes/economia/_archivos// 000000_Informes $/ 800000$ Exportaciones $\%$ $20 \mathrm{e} \% 20$ importaciones $\% \overline{2} 0$ pesqueras $\% 20$ Informes\%20Anuales/000011_2016/170517 Exportaciones\%20e\%20Importaciones\%20 Pesqueras\%202016.pdf.

Tsai YL, Lin YC, Chou PH, Teng PH, Lee PY. 2012. Detection of White Spot Syndrome Virus by polymerase chain reaction performed under insulated isothermal conditions. J Virol Methods. 181 (1): 134-137.

Recibido: 05-02-2018

Aceptado: 01-08-2018 